\title{
The interdisciplinarity revolution
}

\section{(La revolución de la interdisciplinariedad)}

\author{
Vincenzo Politi* \\ CEA - French Alternative Energies and Atomic Energy Commission
}

\begin{abstract}
Contemporary interdisciplinary research is often described as bringing some important changes in the structure and aims of the scientific enterprise. Sometimes, it is even characterized as a sort of Kuhnian scientific revolution. In this paper, the analogy between interdisciplinarity and scientific revolutions will be analysed. It will be suggested that the way in which interdisciplinarity is promoted looks similar to how new paradigms were described and defended in some episodes of revolutionary scientific change. However, contrary to what happens during some scientific revolutions, the rhetoric with which interdisciplinarity is promoted does not seem to be accompanied by a strong agreement about what interdisciplinarity actually is. In the end, contemporary interdisciplinarity could be defined as being in a 'pre-paradigmatic' phase, with the very talk promoting interdisciplinarity being a possible obstacle to its maturity.
\end{abstract}

KEYWORDS: Interdisciplinarity; Rhetoric of Science; Scientific Disciplines; Scientific Revolutions; Thomas Kuhn

RESUMEN: La investigación contemporánea sobre la interdisciplinariedad es descrita a menudo como si implicara cambios importantes en la estructura y fines de la empresa cientifica. A veces es incluso caracterizada como una forma de revolución cientifica kubniana. En este artículo se analizará la analogía entre la interdisciplinariedad y las revoluciones cientificas. Se sugerirá que el modo en que se promueve la interdisciplinariedad es similar al modo en que se describe y defiende un nuevo paradigma en algunos episodios de cambio cientifico revolucionario. Sin embargo, al contrario de lo que sucede durante las revoluciones cientificas, la retórica con la que se promueve la interdisciplinariedad no parece venir acompañada por un fuerte acuerdo acerca de lo que es realmente dicha interdisciplinariedad. En definitiva, la interdisciplinariedad contemporánea se encuentra en una fase pre-paradigmática, siendo un posible obstáculo para su madurez el discurso mismo que promueve la interdisciplinariedad.

PALABRAS CLAVE: Interdisciplinariedad; retórica de la ciencia; disciplinas cientificas; revoluciones cientificas; Thomas Kuhn.

* Correspondence to: Vincenzo Politi. CEA-Saclay, bat. 703, 91191 Gif-sur-Yvette, France. - vin.politi@gmail.com - http://orcid.org/00000002-5753-3196

How to cite: Politi, Vincenzo. (2019). «The interdisciplinarity revolution»; Theoria. An International Journal for Theory, History and Foundations of Science, 34(2), 237-252. (https://doi.org/10.1387/theoria.18864).

Received: 23 February, 2018; Final version: 9 October, 2018.

ISSN 0495-4548 - eISSN 2171-679X / (C) 2019 UPV/EHU

This article is distributed under the terms of the

Creative Commons Atribution 4.0 Internaciona/ License 


\section{Introduction}

Contemporary interdisciplinary research is often described as bringing some important changes in the structure and aims of the scientific enterprise. Sometimes, it is even characterized as a sort of Kuhnian scientific revolution. But is interdisciplinarity really bringing a revolution into science?

In this paper, I take the analogy between interdisciplinarity and scientific revolutions seriously. The way in which interdisciplinarity is described and promoted will be analysed by using the tools developed by historians and philosophers of science to study scientific change. Such an analysis will allow me to assess the extent, but also the limits, of the changes that interdisciplinarity could bring into science.

In $\$ 2$, I will briefly examine the definition(s) of interdisciplinarity. In $\$ 3$, I show how interdisciplinarity is described as bringing a revolutionary change into the structure of science. In $\$ 4$, I specify which kind of revolution, if any, interdisciplinarity could bring into science. I will suggest that interdisciplinarity could lead to something similar to those episodes of scientific change, such as the transition from the Aristotelian to the Galilean conception of science, which involved the whole disciplinary structure of science rather than one single discipline. In $\$ 5$ I will discuss some disanalogies between scientific revolutions and interdisciplinarity. It will be argued that, contrary to what happens with some scientific revolutions, the rhetoric with which interdisciplinarity is promoted does not seem to be accompanied by a strong agreement about what interdisciplinarity actually is. I conclude, in $\$ 6$, by characterising contemporary interdisciplinarity as being in a 'pre-paradigmatic' phase and by claiming that the talk about interdisciplinarity may actually be an obstacle to its maturity.

\section{What is interdisciplinarity?}

One of the problems of interdisciplinarity is its definition. As recently pointed out by Hoffmann et al. (2013, 1857), 'interdisciplinarity' has been a 'buzzword' for the last four or five decades, despite the lack of a consensus about its precise meaning.

The literature on the topic usually distinguishes between multidisciplinarity (the coordinated effort of different disciplines to solve a shared problem from their own perspective), interdisciplinarity (the integration of different disciplines, at a theoretical or methodological level) and transdisciplinarity (an approach which transcends the boundaries between natural and social sciences, and even questions the very idea of a scientific disciplines) - see, among the others, Choi and Pak 2006; Holbrook 2013; Klein 1990, 2010.

Prima facie, it looks like 'integration' is the key-element for distinguishing interdisciplinarity from other forms of poly-disciplinary research. This view is explicitly defended by Klein, who claims that " $[t]$ he only true interdisciplinarity is integrated interdisciplinarity, [in which] the concepts and insights of one discipline contribute to the problems and theories of another" (Klein 1990, 20). More recently, a similar view has also been endorsed by the authors of the widely cited report of the National Academy of the Sciences (NAS), who define interdisciplinarity as

a mode of research by teams or individuals that integrates information, data, techniques, tools, perspectives, concepts, and/or theories from two or more disciplines or bodies of specialized 
knowledge to advance fundamental understanding or to solve problems whose solutions are beyond the scope of a single discipline or area of research practice. (NAS 2005, 2)

It has been argued, however, that not every interdisciplinary interaction leads to successful integration (Grüne-Yanoff 2016). Many of such interdisciplinary collaborations may simply make use or leading to the production of 'model templates' (Knuuttila and Loettgers 2016), 'repertoires' (Ankeny and Leonelli 2016), or 'migrating models' (Bradley and Thébault 2017).

Moreover, rather than different kinds of activities, multidisciplinarity, interdisciplinarity and transdisciplinarity could be simply regarded as different stages of the same process: a scientific research may begin with the involvement of different disciplines, which, with time, may get integrated and, eventually, may end up breaking disciplinary boundaries. This may be the reason for why some of these terms, especially 'inter-' and 'transdisciplinarity', are often used interchangeably.

Since this paper is not concerned with the definition and classification of the different types of scientific activity, it will follow the common trend which defines interdisciplinarity' and 'interdisciplinary research' in a rather loose sense, to indicate all the types of scientific research involving more than one discipline.

\section{Is interdisciplinarity revolutionary?}

Interdisciplinarity is not a recent phenomenon in the history of science. Many scientific disciplines, like biochemistry, emerged from the interdisciplinary work conducted in the area of partial overlapping of two or more pre-existing disciplines. What is recent is a certain way to talk about interdisciplinarity.

In recent years, interdisciplinarity has started to be viewed as the best way for solving urgent, complex and global problems. Considered to be capable to solve more-or, at least, different-problems than traditional mono-disciplinary research, interdisciplinarity is often viewed as bringing a fundamental change in science. More specifically, interdisciplinarity is described as changing how knowledge is produced, as well as the kind of knowledge which is produced.

Gibbons et al. (1994) and Nowotny et al. (2001), for example, introduce the concept of 'Mode-2 knowledge production'. Contrary to the traditional discipline-bounded Mode1 , Mode- 2 challenges the internalist ideal of a pure scientific activity, solely concerned with its own esoteric problems, and, instead, takes place within the three-folded helix of science-society-institutions. Interdisciplinarity, therefore, is considered to be capable of breaking the boundaries among scientific disciplines, as well as between science, on the one hand, and public institutions and society, on the other.

It has also been maintained that a new form of knowledge-that is, 'mutual knowledge'-“emerges as novel insights are generated, disciplinary relationships redefined, and integrative frameworks built" (Klein 2008, 119). Recently, interdisciplinarity has been defined as providing "a vibrant new dimension of knowledge production" (Frodeman et al. 2010, iv).

Although it is not entirely clear 'how' such a new kind of knowledge is actually produced, or to 'what' it amounts to, it is undeniable that the recent talk surrounding interdis- 
ciplinarity describes it as bringing a radical change in science. Sometimes, it is even characterised as being somehow analogous to what Kuhn defines as 'scientific revolutions'.

Kuhn $(1996 /[1962])$, it is worth remembering, develops a cyclic model of the growth of science in which periods of normal science are disrupted by so-called scientific revolutions. During periods of normal science, the scientific activity is guided by a dominant paradigm, which comprises theoretical and metaphysical assumptions, values, problem-solving methods, and upon which the members of the scientific community maintain a consensus. In virtue of such a consensus, scientists can work on the resolution of the problems posed and in the ways dictated by the paradigm itself, without questioning the foundations of the scientific enterprise at every step. When scientists face a high number of recalcitrant problems, the consensus upon the paradigm may break. This situation may lead to a crisis, which in turn opens the way to a period of extraordinary (or 'non-normal') research, during which alternative paradigms are taken into consideration. The revolution is completed when the scientific community finally reaches a consensus upon a new paradigm, which overthrows the old one, and marks the beginning of a new period of normal research. A scientific revolution can be then described as a 'paradigm shift'. The pre- and post-revolution paradigms are deemed by Kuhn as incommensurable, because they lack a 'common measure' for the objective comparison of their theoretical languages, methodologies and world-views. This is, in a nutshell, Kuhn's model of scientific revolutions.

Some scholars employ the Kuhnian jargon to characterise interdisciplinarity. Funtowicz and Ravetz (1993), for instance, talk about 'post-normal science', with reference to the scientific research conducted under risk and in a situation in which "facts [are] uncertain, values in dispute, stakes high and decisions urgent" (Funtowicz and Ravetz $1993,735)$. This is not the place to analyse and assess the concept of post-normal science, as many have already done-see, for example, Turnpenny et al. (2011). Furthermore, it must be stressed that post-normal science is not the same thing of, nor it can be completely reduced to, interdisciplinarity. It is true, however, that a great deal of interdisciplinary research-such as, for instance, the research about global climate change or about ecological issues - could be easily labelled as 'post-normal' in the Funtowicz and Ravetz's sense. For the present purposes, it is enough to highlight how the very expression 'post-normal science' clearly echoes the Kuhnian jargon, to the point that it would be legitimate to wonder whether what Funtowicz and Ravetz are talking about is, in a way or in another, a form of 'revolutionary science'.

More recently, an explicit connection between the Kuhnian concept of a scientific revolution and interdisciplinarity has been made by Pohl et al. (2008) who argue that interand transdisciplinary science are inherently revolutionary. Repko and Szostak (2008) furthermore explain:

The Kuhnian distinction between revolutionary and normal science was undoubtedly overdrawn and has now been supplanted in the study of science by more recent debates. [...] However, the Kuhnian distinction has useful implications for the present discussion [on interdisciplinarity]. Scholars closely following disciplinary methodologies would clearly fall within the 'normal science' category. Inter- disciplinarians are more likely to celebrate grand new syntheses that set scholars on entirely new research trajectory: these would qualify as 'revolutionary science'. (Repko and Szostak 2008, 6) 
It must be specified that talking about interdisciplinarity in the context of theories of scientific change and revolutions is not a novelty. In fact, many scholars consider that scientific revolutions come together with interdisciplinary practice. It has been argued, for example, that the strict disciplinary structure of medieval university was not fit for driving scientific progress. In fact, " $[\mathrm{t}]$ he scientific revolution happened for the most part outside the universities. [...] The term 'Renaissance man' is apposite: these people were not specialists in a discipline, but dabbled in various branches of knowledge" (Turner 2010, 16).

Kuhn (1993) himself seemed to agree on this point. In part influenced by the work of Wise (1993), who examines the interconnection between the practices of different scientific fields, as well as within scientific fields and a larger cultural milieu, he realised that, for example, an episode such as the so-called Chemical Revolution was made possible by developments in physics.

The aim of this paper, however, is not to examine the potential role of interdisciplinary research in scientific revolutions. Rather, in the following sections it will be examined whether contemporary interdisciplinary research, by and in itself, is bringing a sort of revolution into science.

\section{The Anthropology of Revolutionary Scientific Changes}

It may be objected that the analogy between interdisciplinary science and scientific revolutions is superficial or even misleading and that, therefore, it should be ignored. In fact, while a Kuhnian revolution is the replacement of an old paradigm with a new one within a discipline, such as physics or chemistry, interdisciplinarity seems to change, or, at least, to question the boundaries of the disciplinary structure of science. As some historians and philosophers of science have shown, however, it is possible to use the Kuhnian machinery to describe episodes of revolutionary scientific changes affecting the structure of science as a whole.

One of such episodes is the transition between the Aristotelian and the Galilean science. Such a transition did not involve theoretical changes within a particular discipline. In fact, the so-called Aristotelians cannot be attached just to metaphysics, physics, mathematics, astronomy or poetics, but to the whole bunch of disciplines forming Aristotle's complex disciplinary system. Similarly, the so-called Galileans did not attack a specific theory or discipline but, rather, they challenged the principles behind the dominant hierarchy of the sciences.

This episode is analysed from a Kuhnian perspective by Biagioli (1990), in his classic paper The Anthropology of Incommensurability. Biagioli is not interested in the formal and 'synchronic' analysis of the incommensurability between two competing paradigms, but, rather, in the 'diachronic' emergence of communication failures. He wants to show how the communication breakdowns which, for Kuhn, are occasionally experienced by the supporters of two competing paradigms during a scientific revolution do not depend only on the logical and semantic features of a pair of conflicting theoretical languages. Rather, for Biagioli, the breakdowns in cross-paradigmatic communication may be caused by the behaviour of the very participants of the communication. More than with issues of meaning change and ontological discontinuity, incommensurability may have to do with the rhetorics and ambitions of two competing intellectual communities. This is 
why Biagioli defines his own work as an 'anthropological' study of scientific revolutions and incommensurability.

In Biagioli's view, the debates between Aristotelians and Galileans were not characterized by a genuine lack of mutual understanding but, rather, by the unwillingness of the two parties to communicate and understand the respective opponents.

The Aristotelian philosophers tended to be dismissive of Galileo's views in a rather a priori fashion. Such an attitude was driven by the dominant conception of science of the time. Up until then, and under the long lasting Aristotelian paradigm, science was considered to be, essentially, the study of qualities. Within this framework, philosophical speculation occupied the top position in the hierarchy of knowledge. In short: it is not like the Aristotelian philosophers disagreed with Galileo because they misunderstood him; rather, they did not want to communicate with him, because they did not consider him to be a real scientist to begin with.

As a reaction, Galileo and the Galileans exasperated the quantitative and mathematical aspects of their writings. They adopted, that is, a 'mathematical elitism', which deepened the communication divide with their rivals. This behaviour is epitomized by Galileo's Dialogue on the Two Chief World Systems, in which the characters of Sagredo and Salviati, representing the Galilean perspective, actually ridicule the simple-minded Simplicio, who represents a straw-manned and caricatural version of the Aristotelian philosopher. Galileo employs the so-called 'epideiectic', or 'ceremonial', rhetoric, which assumes that the audience is already sympathetic with the theses which are supposed to be proven. This is why, at a closer look, Galileo's Dialogue is anything but a genuine dialogue (Biagioli 1990, 185191).

The controversy between Galileo and the Aristotelians also possessed an ethical dimension. For Galileo, the Aristotelians' stubbornness to ignore mathematics was immoral, a sign of their unwillingness to track the truth. For the Aristotelians, Galileo was simply too narcissist and too busy collecting new facts rather than trying to understand them properly. The lack of communication between Galileans and Aristotelians, therefore, was symptomatic of deep differences between the professional ethos of the two groups.

At the basis of the behaviour of both Aristotelians and Galileans there was a competition for academic prestige and recognition. Up until the Rennaissance, the Aristotelian doctrine had been considered as 'the' science. Aristotelians occupied all the academic positions and a university career was simply precluded to those who did not follow the dominant paradigm. Mathematics was considered to be a lesser science and, as a consequence, mathematicians struggled to enter academia. Indeed, Galileo managed to pursue his research from outside academia and thanks to the patronage-which, from a contemporary perspective, could be considered as a sort of 'private funding' - of the de' Medici family (Biagioli 1993). Given the climate of the time, it appears obvious that the Galileans attempted to ridicule the Aristotelian approach in order to breach into academia, while the Aristotelians dismissed the Galilean method in order to protect their position.

It would be far too easy, however, to dismiss the deadlock between the Aristotelians and the Galileans as a mere sociological phenomenon, which should be of no concern to philosophers interested in the epistemic elements of science. One of the issues arising from the phenomenon of scientific revolutions is how to make sense of the so-called 'prospective rationality', in virtue of which scientists end up supporting a new paradigm which is not fully developed and not fully confirmed yet, but which comes to be accepted for extra-em- 
pirical reasons. The sociological and rhetorical aspects of the conflict among competing professional groups cannot be disentangled from the epistemological problem of choosing the best paradigm. In fact, such extra-epistemological aspects can actually drive and facilitate the choice. As Biagioli points out, "the legitimation of radically new theories or world views may require revolutions in the social hierarchy of disciplines and the emergence of new socio-professional groups" (Biagioli 1990, 188). ${ }^{1}$

In short, following Biagioli, it is easy to see how neither the Artistotelians nor the Galileans really wanted to engage in a genuine conversation, and how both groups developed rhetorical strategies to discredit or diminish the adversary. Such a stubbornness and refusal to communicate, fueled by a good dose of epideiectic rhetoric, moralism and desire of professional recognition, cemented the sense of communitarian identity and the cohesion of both the Aristotelians and the Galileans. In turn, the formation of such a strong sense of communitarian identity - which facilitated the communication among the members of the same community, but prevented it among the members of different communities-allowed the further articulation and refinement of the very theories around which the two conflicting paradigms had been developed. Therefore, the rhetoric-fuelled communication divide played a positive epistemic role, because it pushed for an improvement and a refinement of the two conflicting views.

If, as it is claimed by many, contemporary interdisciplinarity is bringing a revolution into science, then such a revolution involves the disciplinary structure of science as a whole, not just a change of theory within a particular discipline. Therefore, it is possible to see whether the ways such a change is implemented conforms to Biagioli's model.

Similarly to what happens during some revolutions, interdisciplinarity is not always or not only endorsed on the basis of empirical data in favor of its success. Some interdisciplinary collaborations have been successful; the results of other interdisciplinary projects, however, are yet to be seen. That some specific interdisciplinary projects worked well in the past, however, is not a sufficient reason to think that interdisciplinarity in general' will always work. Whether a particular interdisciplinary approach will actually solve a particular complex problem can be decided only with hindsight. The situation for the supporters of interdisciplinarity, therefore, is akin to the situation of the defenders of Galileo's mathematization during their dispute with the Aristotelians, when they found themselves defending a method which had not been demonstrated to be successful. Similarly, since it is so difficult to assess its future merits, the discourse surrounding interdisciplinarity is steeped of rhetorical elements.

Epideiectic strategies are used in some high-level policy reports from funding agencies, in which the value of interdisciplinarity and a sympathetic attitude toward it seem to be taken for granted. For example, in the already mentioned report of the NAS, it is claimed, in a rather triumphalist way, that interdisciplinarity

1 The scientific revolution which took place through Galileo's mathematization is a massive topic in the history and philosophy of science. Additional studies addressing the changing disciplinary landscape at Galileo's time are developed by, among the others, Dear 1995, 2011; Lennox 1986; Mancosu 1996. In any case, it is worth specifying that the present paper is not about Galileo. Rather, Biagioli's interpretation of Galileo is here used to assess the extent of the assess the extent of the (alleged) revolutionary change that contemporary interdisciplinary would bring into science. 
can be one of the most productive and inspiring of human pursuits-one that provides a format for conversations and connections that lead to new knowledge. As a mode of discovery and education, it has delivered much already and promises more-a sustainable environment, healthier and more prosperous lives, new discoveries and technologies to inspire young minds, and a deeper understanding of our place in space and time. [...] Interdisciplinary research and education are inspired by the drive to solve complex questions and problems, whether generated by scientific curiosity or by society, and lead researchers in different disciplines to meet at the interfaces and frontiers of those disciplines and even to cross frontiers to form new disciplines. (NAS 2005, 16)

In another report, this time of the National Science Foundation (NSF), interdisciplinarity seems to be the panacea capable of solving pretty much all the ills of the world.

From global sustainability to renewable energy to the origins of life in the cosmos to forecasting and potentially mitigating economic upheavals, the largest scientific challenges-and those that may hold the greatest opportunity for transformative technological solutions into the 21 st century - are interdisciplinary in nature. The skills required from a new generation of trained scientists and engineers to address these challenges have been and continue to be broadly discussed and debated. (NSF 2008, 7)

Sometimes, the rhetoric surrounding interdisciplinarity may also take moralistic tones: not to engage in interdisciplinarity-and, therefore, not to engage in the structural changes of academia interdisciplinarity may lead to-is considered to be just 'wrong'. At the beginning of an article published in The Scientist, Khan (1994) claims that, in order to solve the most pressing problems, interdisciplinary research must be considered as a scientific as well as social imperative. Khan spends the rest of the article examining how the potential obstacles to interdisciplinarity can be overcome. In particular, he targets the structure of academia and the basic funding mechanisms. Similarly, Nicolescu (2002) criticizes the current academic system, which can be 'nationalistic', 'feudalistic' and 'protectionist', and argues that its barriers can be broken through interdisciplinarity.

Finally, it is not too difficult to see that one of the reasons for supporting interdisciplinarity could be the desire of recognition of some existing professional groups and the emergence of new ones. It is often argued that the resolution of complex, real-world problems requires the integrated effort of both the natural and the social sciences, the boundaries of which should be 're-configured' (Barry and Born 2013). Apart from solving some problems, such a reconfiguration would also give more prominence to those working in the social sciences as well as in the arts and humanities. To echo Biagioli, the legitimation of a new way of doing science may require revolutions in the social hierarchy of disciplines and the emergence of new socio-professional groups.

All in all, it looks like the talk about contemporary interdisciplinarity and the talk about a new method capable of bringing a revolutionary change in our conception of science share many similarities. There are, however, some important dissimilarities which deserve to be analyzed and discussed. The aim of such an analysis is not to show that contemporary interdisciplinarity is not like the type of revolutionary changes discussed by Kuhn or Biagioli after all. Rather, the analysis of the analogies and disanalogies between interdisciplinarity and scientific revolutions is used to illuminate up to which point interdisciplinary science does represent a fundamental change in science. 


\section{Beyond the social and rhetorical elements of the talk about interdisciplinarity}

In the previous section, I explained how, following Biagioli, in some scientific revolutions professional motivations, rhetorical manoeuvres and epistemic elements are all intertwined. The communicative isolation into which the members of a scientific group force themselves, driven by some rhetorical strategies, and characterised by the refusal of engaging with the competitors, allows them to reflect on, and refine, their group commitments. I also claimed that the talk about contemporary interdisciplinarity is characterized by a rhetoric akin to that driving and facilitating some types of revolutionary scientific change. It remains to be seen whether the rhetoric surrounding the talk about interdisciplinarity serves the same function as the rhetoric driving some episodes of revolutionary scientific change.

To begin with, it should be wondered whether the supporters of contemporary interdisciplinarity agree on what the interdisciplinary method is supposed to be.

On the one hand, however, the actors of interdisciplinarity (i.e., scientists doing interdisciplinary research) are not always very clear on the methodologies they employ. As observed by Robertson et al. (2003), for example,

while the desiderability of interdisciplinary inquiry has been widely acknowledged, indeed has become 'the mantra of science policy', the methods of interdisciplinary collaboration are opaque to outsiders and generally remain underdescribed. Many have analysed interdisciplinarity, especially in relation to the creation of new disciplines and institutions. [...] Still, there currently persists a silence about the methods of interdisciplinary collaboration itself. (Robertson et al. 2003, 21)

On the other hand, the analysts of interdisciplinarity (i.e., historians, sociologists and philosophers of interdisciplinary science) do not agree on whether such a method exists, or even whether it would be desirable to find it.

Some of them attempt to provide prescriptive rules for interdisciplinarity. Newell (2007), for example, lists a series of necessary steps to solve complex problems which, jointly considered, should constitute the interdisciplinary method. The first steps of Newell's list_-such as 'defining the problem', 'determining the relevant disciplines for solving it' and 'gathering all relevant disciplinary knowledge'-are taken from a disciplinary perspective. The second set of steps-i.e., 'identifying conflicts', 'resolving conflicts by creating a common ground' and, indeed, 'creating a common ground'-are proper of the interdisciplinary research.

An issue with Newell's prescriptions for interdisciplinarity is that, when looked at in enough depth, every item in his list is hugely problematic. For example, in the context of interdisciplinarity, something like his first step-'defining the problem'-is not immediate or methodologically innocent. As pointed out by Alvargonzález (2011), in fact, problems are formulated from within disciplines which are 'operationally closed' around theories, principles and material objects (i.e., experimental devices). Different disciplines may define the same problem in different ways. Furthermore, it is not entirely clear whether problems could be defined from a discipline-free perspective. Other steps in Newell's list, such as 'resolving conflicts by creating a common ground', are the very problems that interdisciplinarity should solve. In short, it looks like Newell's tells us what to do, but not how to do it. Or, more polemically put, he tells us what the problems of interdisciplinarity are, without indicating a way for solving them. 
Bammer (2013), who is also concerned by the lack of an accepted methodology for integrating disciplines in order to solve complex-problems, envisions a new field of research, called Integration and Implementation Sciences. One of the chief projects that such a new field should conduct is, in Bammer's view, the creation of a global database collecting all the instances of successful interdisciplinary research. By developing such a Big-Science/BigData project, some sort of pattern followed by successful interdisciplinary research should emerge.

Other analysts of interdisciplinarity, however, question the very possibility of establishing, once and for all, what the 'method of interdisciplinarity' is. Krohn (2010), for example, argues that the study of interdisciplinarity should proceed on a case-by-case basis. Studying examples of successful interdisciplinary research, however, would not lead to the recognition of some general rules for interdisciplinarity, as Bammer would contend. This is because, for Krohn, each of such cases is self-contained and, therefore, it cannot be thought of as an 'exemplar' for interdisciplinary practice in general. In Krohn's view, therefore, looking at many cases of interdisciplinarity can facilitate the acquisition of tacit skills, habits and intuitions, but does not lead to the discovery of 'the' method of interdisciplinary research.

Something similar is also argued by Frodeman (2014), for whom interdisciplinarity does not require fixed rules and specific methodologies, but it is more a matter of scientists' virtues, such as "the openness to new perspective, a willingness to admit the inadequacies of one's own point of view, to be wrong and to play the fool, and generosity in interpreting the position and motives of others." (Frodeman 2014, 48). In his view, trying to uncover the general rules and methods of interdisciplinarity is a residual of the traditional tendency to create disciplines with relatively stable and well defined boundaries. But the aim of interdisciplinarity is precisely breaking such boundaries. Therefore, it would be contradictory to capture the essence of interdisciplinarity but putting interdisciplinarity itself within the boundaries of a new discipline. For Frodeman, therefore, the temptation to 'disciplinize interdisciplinarity', à la Bammer, should be avoided at all costs.

In short, the supporters of interdisciplinarity do not seem to agree on the existence of a method of interdisciplinary research, nor do they seem to agree on whether such an issue should be investigated at all.

When it comes to the types of problems to be solved, it looks like there is a general consensus about the fact that contemporary interdisciplinarity is useful to solve 'complex problems', or 'real-life problems', or 'big challenges'-or all of these things. It is however unclear whether such 'complex problems' or 'big challenges' can be solved at all. As Hansson (1999) (maybe rhetorically) asks, "[d] o we really think that their scale, complexity and level of difficulty are such that they can be solved in the foreseeable future, if even by a gigantic, concentrated, cooperative effort?" (Hansson 1999, 342-343).

Similarly, Alvargonzález (2011) questions whether the problems interdisciplinarity is called to solve are scientific problems to begin with. In his view, "the assumption that these problems have a scientific solution (in post-normal science or in future unified transdisciplinary science) may be an illusion” (Alvargonzález 2011, 401).

In the end, problems about the definition of the kind of problems to be solved and of how to solve them go hand in hand with the problem of the method(s) of interdisciplinarity. Without an agreed upon method, or set of methods, for posing and solving problems, it may not always be clear when, and if, a problem has actually been solved at 
all. Indeed, one of the issues associated with the practice of interdisciplinarity is the difficulty of assessing its outcomes. As Klein claims, "[c]riteria for judgement constitute the least understood aspect of interdisciplinarity, in part because the issue has been the least studied and in part because the multiplicity of tasks seems to militate against a single standard" (Klein 1996, 210).

In concluding this section, a few remarks are in order. Despite its inherent problems and difficulties, it is not claimed here that interdisciplinarity is useless and should not be pursued at all. Against such an overly-critical position, one could easily respond by examining the motivations behind interdisciplinarity. Interdisciplinary research is not motivated only by the inherent complexity of the world or by the problems arising at the boundaries of different disciplines. Some of its drivers, such as the need solve societal problems and the challenges and possibilities created by new technologies, may be of a more praxeological nature (NSF 2008, 26-40).

Furthermore, although interdisciplinarity may not be able to solve all the pressing and urgent problems the world is facing, it can try, at least, to ameliorate the current situation. An absolutely 'right' (but late) solution to some problems may be the enemy of the good: waiting to gain the true knowledge of the fundamental levels of reality could be unwise. As Frodeman (2014) would say, relying on the knowledge produced by traditional disciplines may simply be unsustainable. Nevertheless, although many things about it can be appreciated, it does not mean that interdisciplinarity is problem free and philosophical analysis should uncover and discuss such problems.

Finally, it must be stressed that objections to interdisciplinarity are not uncommon. Indeed, many of such criticisms are developed in the light of some of the issues discussed above-i.e., the problem of whether there is a general method of interdisciplinarity, the problem of how to assess the outcome of interdisciplinary research, and so on. However, it must be specified that this section was not about the criticisms to interdisciplinarity moved from outside the community of its supporters. Rather, this section discussed the lack of a consensus on some foundational issues within such a community. As it will be clarified in the next section, this is one of the main differences between scientific revolutions and interdisciplinarity.

\section{Interdisciplinarity: in search of a paradigm?}

Contemporary interdiscipinarity is sometimes compared to scientific revolutions-clearly, not to intra-disciplinary revolutions, such as the Chemical Revolution, or the transition from Newton's classical mechanics to Einstein's relativity in physics but, rather, to a kind of change affecting the whole hierarchy of science, as the emergence of the Galilean method. As in those episodes, the talk about interdisciplinarity is characterised by a sort of 'anti-disciplinarian' rhetoric. The value of interdisciplinarity is often assumed rather than proven, and its necessity in the faces of complex problems and big challenges can be defended on moral grounds.

There is, however, an important difference between scientific revolutions and interdisciplinarity. During a scientific revolution, rhetorical and epistemological elements go hand in hand. In these cases, rhetoric may function as an isolating mechanism: dismissing the competitors' views through rhetorical manoeuvres may allow the members of a community 
to focus on their own paradigm, in order to develop and strengthen it. In the case of interdisciplinarity, however, it seems that, behind its anti-disciplinarian rhetoric, there is no real consensus among its supporters on how the 'new' science should look like. One could even say that the 'post-normal science' Funtowicz and Ravetz (1993) talk about is actually in its 'pre-paradigmatic' phase: the interdisciplinary paradigm is still a work in progress.

It may be argued that what the present analysis shows is just that, despite the way it is often characterized, interdisciplinarity is not like a Kuhnian revolution after all. This would be a problem only if the universal validity of the Kuhn's model of science is taken for granted, and only if Kuhnian revolutions are considered to be the only important scientific changes worth of discussion. But one can just disagree with Kuhn and, therefore, characterise the change that interdisciplinarity may bring into science in different terms. The main aim of this paper, however, is not to determine whether contemporary interdisciplinarity is actually an instance of Kuhnian revolutions. Rather, the analogy with Kuhnian revolutions is used to examine some feature of interdisciplinarity. That behind the rhetorics of interdisciplinarity there is a lack of agreement about its methods and the ways of assessing its problem-solving power, in fact, is a problem for understanding how interdisciplinarity can change science and produce a new kind of knowledge in any significant way, no matter how such a 'change' is described.

It may also be argued that the strength of interdisciplinarity is precisely in the lack of a consensus upon a monolithic 'interdisciplinarity paradigm'. The value of interdisiciplinarity may be its inherent pluralism, which probably makes it more resilient in the face of the complex problems and global challenges it is called to solve. But unbounded pluralism poses its problems too, especially when the lines between natural and social sciences, and between the sciences and the art and humanities, begins to be reconfigured. It may turn out that, while in some cases of revolutionary scientific changes, as the one described by Biagioli, the disciplinary hierarchy of the sciences was altered, what interdisciplinarity aims at doing is to wipe out any disciplinary hierarchy of the sciences, or even any idea of what counts as 'scientific'. This is what seems to be argued, for instance, by Nicolescu (2002) and, to some extent, by Frodeman (2014). Unfortunately, this is not the place for discussing this problem, which deserves to be treated separately. It suffices to say that such a view may go well beyond the concept of 'scientific change'.

Finally, what I have analysed in this paper has not much to do with specific interdisciplinary collaborations, but more with how interdisciplinarity 'in general' is talked about. As rightly pointed out by Mäki (2016)

[t]alk about interdisciplinarity is different from interdisciplinarity present in scientific practice.
The two may be (and often are) out of phase with one another. On the one hand, there is quite
some empty, pretentious or misguided talk about interdisciplinarity; on the other, ther is much
unrecognized or misunderstood genuine interdisciplinarity in the actual practice of science. [...]
The ways in which the two-talk and practice-are connected are to be examined separately.
Even if different, and sometimes independent, talk and practice share something important in
common: presently they both grow. (Mäki 2016,330 )

It could be legitimately asked if there is anything regarding the talk about interdisciplinarity, as opposed the actual practice of interdisciplinarity, worth of philosophical discussion. One could agree that some of the ways in which the 'revolutionary' impact of interdiscipli- 
narity is advertised may blow things out of proportions; yet, at the same time, one could also claim that the consequences of such a "pretentious or misguided talk", if any, are negligible.

The talk about interdisciplinarity, however, should not be neglected. As recognised by many, interdisciplinarity has become a "mantra"-an expression used, among the others, by Metzger and Zare (1999, 642), Robertson et al. $(2003,21)$ and Klein $(2008,116)$.

It would also be possible to characterise interdisciplinarity as a 'value' guiding scientists and policy makers in their choice of theories or research project-i.e., a theory or project should be chosen over its competitors if its interdisciplinary. Interdisciplinarity did not acquire such a status only on the basis of the success of specific interdisciplinary research projects: as a matter of fact, the success of some interdisciplinary research, such as, for example, climate science, is highly contested-see, for example, Sarewitz $(1996,68)$. The talk about interdisciplinarity, therefore, may have played a role in the way in which the practice of interdisciplinarity is perceived and, also, promoted. More specifically, it may have constrained the type of questions one asks about interdisciplinarity.

There are (at least) two types of questions which can be asked about interdisciplinarity itself: the how-questions (i.e., "how can we implement or encourage interdisciplinarity?") and the why-questions (i.e., "why should we implement or encourage interdisciplinarity?"). It looks like the majority of the actors and the analysts of science are mainly preoccupied with the first type of questions: that is, with how interdisciplinarity and interdisciplinary integration can be achieved. Often this preoccupation takes the form of sociological analyses of the institutional barriers which may prevent and prevent successful multi- and inter-disciplinary collaborations, with various suggestions on the possible ways for overcoming them.

These how-questions put the horse before the cart. The interest in how to facilitate, encourage and achieve interdisciplinarity is driven by the presupposition that interdisciplinarity actually works; and, also, that it works better than the scientific research conducted within the boundaries of traditional disciplines. The desirability, effectiveness and value of interdisciplinarity seems just to be taken for granted, without further qualification. Apart from asking questions about how interdisciplinarity can be facilitated and implemented, interdisciplinarity itself can be (and, maybe, should be) questioned. This can be done by changing the type of questions are usually asked about interdisciplinarity. That is, by changing the talk about interdisciplinarity.

\section{Conclusions}

Instead of treating them as uninteresting contingencies or external aspects of the scientific enterprise, some philosophers of science have come to accept the idea that sociological and rhetorical elements can be part of theories of the rationality of science. For instance, during some scientific revolutions, such elements may drive the process of paradigm choice by creating a communicative divide between the members of two competing socio-professional groups. Such a communicative isolation allows the members of each group to think about and refine their own paradigm. Sometimes, however, the same rhetorical strategies may be an impediment to the development of a paradigm. The validity and necessity of contemporary interdisciplinarity is often taken for granted, but there is still a lack of consensus about 
its foundations among its own supporters. The talk about interdisciplinarity may hinder its maturation by constraining the type of questions we ask about interdisciplinarity itself.

\section{REFERENCES}

Alvargonzález, David. 2011. Multidisciplinarity, interdisciplinarity, transdisciplinarity and the sciences. International Studies in the Philosophy of Science 25: 387-403.

Ankeny, Rachel and Sabina Leonelli. 2016. Repertoires: A post-Kuhnian perspective on scientific change and collaborative research. Studies in History and Philosophy of Science 60: 18-28.

Bammer, Gabriele. 2013. Disciplining interdisciplinarity: Integration and implementation sciences for researching complex real-world problems. Canberra: ANU Press.

Barry, Andrew and Georgina Born., eds. 2013. Interdisciplinarity. Reconfigurations of the social and natural sciences. Oxon: Routledge.

Biagioli, Mario. 1990. The anthropology of incommensurability. Studies in History and Philosophy of Science 21: 183-209.

Biagioli, Mario. 1993. Galileo, Courtier. Chicago: University of Chicago Press.

Bradley, Seamus and Karim Thébault. 2017. Models on the move: migration and imperialism. Studies in History and Philosophy of Science, forthcoming.

Choi, Bernard and Anita Pak. 2006. Multidisciplinarity, interdisciplinarity and transdisciplinarity in health research, services, education and policy: 1. definitions, objectives, and evidence of effectiveness. Clinical and Investigative Medicine 29: 351-364.

Dear, Peter. 1995. Discipline and experience: The mathematical way in the scientific revolution. Chicago: University of Chicago Press.

Dear, Peter. 2011. Mixed mathematics. In Peter Harrison, Ronald Numbers and Michael Shank, eds., Wrestling with science: From omens to science, 149-172. Chicago: University of Chicago Press.

Frodeman, Robert. 2014. Sustainable knowledge: A theory of interdisciplinarity. New York: Palgrave Macmillan.

Frodeman, Robert, Klein, Julie T. and Pacheco, Roberto C.S., eds. 2010. The Oxford handbook of interdisciplinarity. Oxford: Oxford University Press.

Funtowicz, Silvio and Jerome Ravetz. 1993. Science for the post-normal age. Futures 31: 735-755.

Gibbons, Michael, et al. 1994. The new production of knowledge: the dynamics of science and research in contemporary societies. London: SAGE Publications Ltd.

Grüne-Yanoff, Till. 2016. Interdisciplinary success without integration. European Journal for Philosophy of Science 6: 343-360.

Hansson, Bengt. 1999. Interdisciplinarity: for what purpose? Policy Science 32: 339-343.

Hoffmann, Michael, Jan Schmidt, and Nancy Nersessian. 2013. Philosophy of and as interdisciplinarity. Synthese 190: 1857-1864.

Holbrook, Britt. 2013. What is interdisciplinary communication? Reflections on the very idea of disciplinary integration. Synthese 190: 1865-1879.

Khan, Robert. 1994. Interdisciplinary collaborations are a scientific and social imperative. The Scientist 8 , available on line at: https://www.the-scientist.com/opinion-old/interdisciplinary-collaborations-are-a-scientific-and-social-imperative-59085 (last accessed: September 2018)

Klein, Julie T. 1990. Interdisciplinarity: History, theory and practice. Detroit: Wayne State University Press.

Klein, Julie T. 1996. Crossing boundaries: Knowledge, disciplinarities, and interdisciplinarities. Charlottesville, VA: University Press of Virginia.

Klein, Julie T. 2008. Evaluation of interdisciplinary and transdisciplinary research: A literature review. American Journal of Preventive Medicine 35, SS116-123. 
Klein, Julie T. 2010. A taxonomy of interdisciplinarity. In Robert Frodeman, Julie T. Klein, and Roberto C.S. Pacheco, eds, The Oxford handbook of interdisciplinarity, 15-30. Oxford: Oxford University Press.

Knuuttila, Tarja and Andrea Loettgers. 2016. Model templates within and between disciplines: from magnets to gases-and socio-economic systems. European Journal for Philosophy of Science 6, 377 400 .

Krohn, Wolfgang. 2010. Interdisciplinary cases and disciplinary knowledge. In Robert Frodeman, Julie T. Klein, and Roberto C.S. Pacheco, eds., The Oxford handbook of interdisciplinarity, 31-49. Oxford: Oxford University Press.

Kuhn, Thomas S. 1993. Afterwords. In Paul Horwich, ed., World changes: Thomas Kuhn and the nature of science, 311-341. Cambridge: MIT Press.

Lennox, James (1986). Aristotle, Galileo and mixed sciences. In William Wallace, ed., Reinterpreting Galileo, 29-51. Catholic University of America Press.

Mäki, Uskali (2016). Philosophy of interdisciplinarity. What? Why? How? European Journal for Philosophy of Science 6, 327-342.

Mancosu, Paolo. 1996. Philosophy of mathematics and mathematical practice in the seventeenth century. Oxford: Oxford University Press.

Metzger, Norman and Richar Zare. 1999. Interdisciplinary research: From belief to reality. Science 283: 64243.

National Academy of Sciences (NAS). 2005. Facilitating interdisciplinary research. Washington: National Academy Press.

Newell, William. 2007. Decision-making in interdisciplinary studies. In Göktug Morçöl, ed., Handbook of decision making, 245-265. New York: Marcel Dekke.

Nicolescu, B. (2002). Manifesto of transdisciplinarity. Albany, NY: State University of New York Press.

Nowotny, Helga, Peter Scott and Michale Gibbons. 2001. Re-thinking science: Knowledge and the public in the age of uncertainty. Oxford: Polity.

National Science Foundation (NSF). 2008. Impact of transformative interdisciplinary research and graduate education on academic institutions. (No. NSF 09-519). Arlington, VA: National Science Foundation.

Pohl, Christian, et al. 2008. Integration. In Gertrude Hirsch Hadorn., Holger Hoffmann-Riem, Susette Biber-Klemm, Walter Grossenbacher-Mansuy, Dominique Joye, Christian Pohl, Urs Wiesmann and Elisabeth Zemp, eds., Handbook of transdisciplinary research, 411-426. Netherlands: Springer.

Repko, Allen and Rick Szostak. (2008). Interdisciplinary research: Process and theory. London: SAGE Publications Ltd.

Robertson, David, Douglas Martin and Peter Singer. 2003. Interdisciplinary research: putting the methods under the microscope. BMC Medical Research Methodology 3: 20-24.

Sarewitz, Daniel. 1996. Against Holism. In Peter Galison and David Stump, eds., The disunity of science, 6575. Stanford: Stanford University Press.

Turner, Stephen 2010. Knowledge Formation: An analytic framework. In Robert Frodeman, Julie T. Klein, and Roberto C.S. Pacheco, eds. The Oxford handbook of interdisciplinarity, 9-20. Oxford: Oxford University Press.

Turnpenny, John, Mavi Jones and Irene Lorenzoni. 2011. Where now for post-normal Science? A critical review of its development, definitions, and uses. Science, Technology, and Human Values 36: 287-306.

Wise, Norton. 1993. Mediations: Enlightenment balancing acts, or the technologies of rationalism. In Paul Horwich, ed., World changes: Thomas Kuhn and the nature of science, 230-256. MIT Press. 


\section{Acknowledgment}

This paper began to be written during a period of postdoctoral research at the Instituto de Investigaciones Filosoficas of UNAM (Mexico), under the supervision of Prof. Atocha Aliseda. It was finished at LARSIM at CEA (France), where I am a postdoctoral researcher under the supervision of prof. Alexei Grinbaum.

Vincenzo Politr (PhD in Philosophy 2015) is a postdoctoral researcher at the CEA - French Alternative Energies and Atomic Energy Commission (Paris-Saclay, France). Before holding this position, he was a postdoctoral researcher at the Instituto de Investigaciones Filosoficas at UNAM (Mexico City, Mexico). His research is mainly on special types of scientific change, such as specialization and interdisciplinarity. He has published papers in journals such as Synthese, International Studies in the Philosophy of Science and Studies in History and Philosophy of Science.

Address: CEA-Saclay, bat. 703, 91191 Gif-sur-Yvette, France. Email: vin.politi@gmail.com 